\title{
EVALUACIÓN FORMATIVA EN PROYECTOS UNIVERSITARIOS DE APRENDIZAJE-SERVICIO: UN ESTUDIO DIACRÓNICO
}

Formative Assessment in university Service-Learning projects: A diachronic study

Avaliação Formativa em projetos universitários de aprendizagem-serviço: Um estudo diacrônico

Ana Isabel Muñoz Alcón (1)

Marta Nieves Gómez Pérez (2)

María Elvira Zorzo (3)

Proyecto de Aprendizaje-Servicio financiado por la Asociación de Amigos de la UCAV

(1) Universidad Católica de Ávila, España. Teléfono: +34 920251020. Correo electrónico: ana.munoz@ucavila.es

(2) Universidad Católica de Ávila, España. Teléfono: +34 920251020. Correo electrónico: marta.gomez@ucavila.es

(3) Universidad Católica de Ávila, España. Teléfono: +34 920251020. Correo electrónico: maria.elvira@ucavila.es

\section{Resumen}

El establecimiento de vínculos entre la Universidad y la comunidad en que se halla inserta es un reto permanente. Esta relación de enriquecimiento y beneficio mutuo no sólo se cristaliza a través de la transferencia de conocimiento sino también mediante el servicio. Y cuando, dentro de la comunidad, este servicio va dirigido a alumnado con necesidades educativas especiales (NEE), entramos de lleno en el ámbito de la educación inclusiva, alcanzándose objetivos que van más allá de los de mero conocimiento. En el presente artículo se presenta un proyecto de aprendizaje-servicio llevado a cabo por alumnos de Ingeniería de la Universidad Católica de Ávila a lo largo de dos cursos dentro de la asignatura de inglés en un Centro de Educación Especial de adultos. Se describen las distintas fases y formas de evaluación empleadas en el proyecto y se comparan los resultados obtenidos al realizar una evaluación formativa y compartida.

Palabras clave: Aprendizaje servicio; evaluación formativa; evaluación compartida; educación inclusiva 


\begin{abstract}
The establishment of links between the University and the community in which it is inserted is a permanent challenge. This relationship of enrichment and mutual benefit not only crystallizes through the transfer of knowledge but also through service. And when, within the community, this service is aimed at students with special educational needs (SEN), we enter fully into the field of inclusive education, reaching goals that go beyond those of mere knowledge. This paper presents a service-learning project carried out in English class by Engineering students from the Catholic University of Avila over two academic years at a Special Education Center for adults. The different stages and forms of assessment used in the project are described and the results obtained from formative and shared assessment are compared over the two-year period.
\end{abstract}

Keywords: Service learning; formative assessment; shared assessment; inclusive education

\title{
Resumo
}

O estabelecimento de vínculos entre a Universidade e a Comunidade em que está inserida é um desafio permanente. Esta relação de enriquecimento e benefício mútuo não só se materializa, através da transferência de conhecimento, como também através do serviço. Quando, dentro da Comunidade, este serviço é dirigido a estudantes com necessidades educativas especiais (NEE), entramos plenamente no campo da educação inclusiva, atingindo objetivos que vão para além dos objetivos de conhecimento. Este artigo apresenta um projeto de aprendizagem-serviço realizado por estudantes de engenharia da Universidade Católica de Ávila em dois cursos e durante a disciplina de inglês num centro de Educação Especial de Adultos. São descritas as diferentes fases e formas de avaliação utilizadas no projeto e comparados os resultados obtidos na realização da avaliação formativa e partilhada.

Palavras-chave: Aprendizagem-serviço; avaliação formativa; avaliação partilhada; educação inclusiva

\section{Introducción}

El Aprendizaje Servicio (ApS) es una metodología que integra el servicio a la comunidad con el aprendizaje de contenidos, habilidades y valores. Es "una alianza que 
tiende puentes entre las necesidades académicas y las de una comunidad" (Richards y Novak, 2010, p. 47). Entre sus rasgos distintivos se encuentra la cooperación, o trabajo de equipo y colaboración con los receptores de la ayuda; la adquisición de valores por la participación en actividades que los encarnan y fomentan, y la evaluación múltiple, o regulación continua de la experiencia y del trabajo de los participantes. Por lo tanto, el proceso de evaluación de este tipo de proyectos de ApS no se puede limitar a la perspectiva de un solo sujeto evaluador ni tampoco a un único momento ni mucho menos usando un solo tipo de evaluación o de instrumento. Es necesario que sea resultado de una valoración global de numerosos aspectos y que se realice dentro del propio grupo de alumnos y por todos los participantes en el proyecto.

\section{Contextualización}

Al principio del semestre de otoño, en los cursos 2017-18 y 2018-19, dentro de la asignatura obligatoria de inglés (6 créditos ECTS), se propuso a los alumnos de primer curso de cinco Grados diferentes de Ingenierías de la Universidad Católica de Ávila (UCAV) la realización de un proyecto de Aprendizaje Servicio de forma voluntaria. Este consistiría en la presentación de un tema de inglés a nivel básico a un grupo de alumnos del Centro de Educación Especial "La Casa Grande de Martiherrero", situado a $5 \mathrm{Km}$ al noroeste de la ciudad de Ávila (España). Este Centro acoge, en régimen de internado, a más de un centenar de jóvenes y adultos con discapacidades psíquicas. En esencia, se trataba de que los alumnos de Ingeniería se convirtieran por un día en profesores de inglés de estos alumnos con capacidades diferentes. Las edades de los alumnos de Ingeniería estaban comprendidas entre 19 y 29 años. Las de los segundos entre 19 y 45.

\section{Diseño}

La presentación se preparó y realizó en equipos de 2 o 3 personas. Cada equipo de alumnos de la UCAV hizo su presentación en la misma tarde a dos grupos diferentes de unas 8-10 personas. Para presentar el nuevo vocabulario y estructuras a nivel básico, usaron recursos audiovisuales, materiales diseñados por ellos mismos $\mathrm{u}$ objetos relacionados con el vocabulario que debían enseñar. En el curso 2017-18, participaron en el proyecto 36 alumnos (16 de UCAV y 20 de Martiherrero). En el 2018-19, 25 (13 y 12 respectivamente). 
Cada sesión tuvo una duración máxima de 1 hora, contando con 15-20 minutos para la presentación del tema y el resto para actividades participativas (juegos, adivinanzas, competiciones, puzzles y/o quizzes). Para apoyar el aprendizaje, cada equipo preparó un guion. Asimismo, diseñaron algún juego o quizz para comprobar la asimilación de los contenidos.

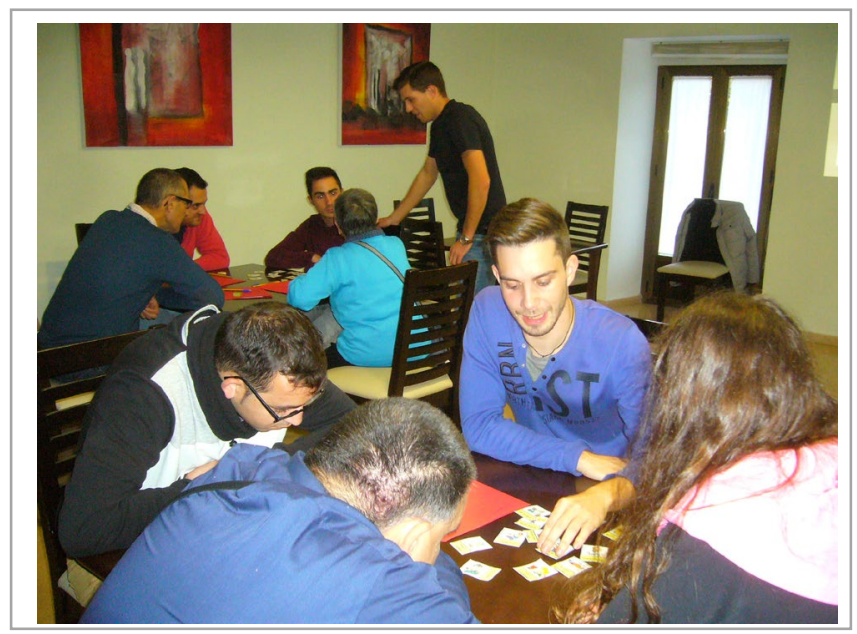

Figura 1. Uno de los equipos de alumnos de Ingeniería UCAV durante una sesión.

\section{Desarrollo}

El proyecto se desarrolló durante los meses de octubre-noviembre de 2017 y noviembre de 2018. Como en todo proyecto de Aprendizaje Servicio, cada una de las tres fases preparación, realización y evaluación- tiene igual relevancia para alcanzar los objetivos propuestos. La tabla 1 recoge en forma sintética la estructura del proyecto.

Tabla 1.

Fases del proyecto de ApS en La Casa Grande en cada curso académico

\begin{tabular}{ll}
\hline FASES & \multicolumn{1}{c}{ ACTIVIDADES } \\
\hline & Visita de la profesora de la asignatura de inglés y algunos \\
& universitarios al Centro de Educación Especial. Visita de instalaciones. \\
Primer contacto con el alumnado. Entrevista con su directora y equipo \\
docente. Organización conjunta de las sesiones del proyecto de \\
aprendizaje servicio. \\
Preparación de materiales y actividades por equipos. \\
Revisión y apoyo a cada equipo por medio de la tutoría con la \\
profesora. \\
Presentación de las sesiones a los alumnos del Centro de Educación \\
Especial por equipos. \\
Evaluación in situ realizada por la profesora y por los alumnos con \\
capacidades diferentes. \\
\hline Sesión de recapitulación y conclusiones del proyecto. Montaje- \\
resumen de la labor realizada. Reflexiones. Realización de un resumen \\
individual en inglés con las conclusiones e impresiones personales. \\
Autoevaluación por equipos. Encuesta anónima individual. \\
\hline
\end{tabular}




\section{Evaluación}

Austin y Rust (2015) destacan cómo la experiencia y la reflexión son los dos aspectos críticos de la educación experiencial de la que el Aprendizaje Servicio forma parte.

La fase de evaluación implica valorar los aprendizajes, el servicio prestado e identificar los logros y retos (Hart, 2015). La autoevaluación es también clave en el proceso de reflexión, lo mismo que compartir lo aprendido y lo logrado. Los distintos actores, medios, técnicas e instrumentos utilizados en la evaluación formativa del proyecto (Hamodi \& López Pastor, 2015) se recogen en la tabla 2.

Tabla 2.

Componentes de la Evaluación Formativa aplicada en el proyecto de ARS

\begin{tabular}{|c|c|c|c|}
\hline Elementos evaluados & Sujetos & Técnicas & Instrumentos \\
\hline \multirow{3}{*}{$\begin{array}{c}\text { Presentaciones y actuación } \\
\text { de los equipos }\end{array}$} & Profesora & Observación & Rúbrica \\
\hline & $\begin{array}{l}\text { Alumnos con } \\
\text { capacidades } \\
\text { diferentes }\end{array}$ & Observación & $\begin{array}{c}\text { Escala de estimación } \\
\text { Likert }\end{array}$ \\
\hline & $\begin{array}{c}\text { Alumnos de } \\
\text { ingenierias }\end{array}$ & Autoevaluación & $\begin{array}{c}\text { Escala de estimación } \\
\text { Likert }\end{array}$ \\
\hline $\begin{array}{c}\text { Expresión escrita en inglés } \\
\text { de los alumnos } \\
\text { universitarios }\end{array}$ & Profesora & $\begin{array}{c}\text { Análisis de } \\
\text { producciones (ensayo } \\
\text { escrito final en inglés } \\
\text { sobre las impresiones } \\
\text { de la experiencia) }\end{array}$ & Rúbrica \\
\hline $\begin{array}{l}\text { Percepción subjetiva de } \\
\text { los aprendizajes realizados }\end{array}$ & $\begin{array}{l}\text { Profesora } \\
\text { Alumnos }\end{array}$ & $\begin{array}{l}\text { Encuesta } \\
\text { Evaluación } \\
\text { compartida }\end{array}$ & Encuesta final \\
\hline
\end{tabular}

En la evaluación de las actuaciones de los equipos, intervinieron tanto la profesora de la asignatura de inglés como los propios alumnos del Centro de Educación Especial y se realizó el mismo día de cada presentación. A posteriori, terminadas las presentaciones de todos los equipos, la profesora y los alumnos tuvieron una sesión final de recapitulación y conclusiones, en que los alumnos participantes en el proyecto realizaron en equipo la autoevaluación de sus propias actuaciones (Figuras 2 y 3 ). 


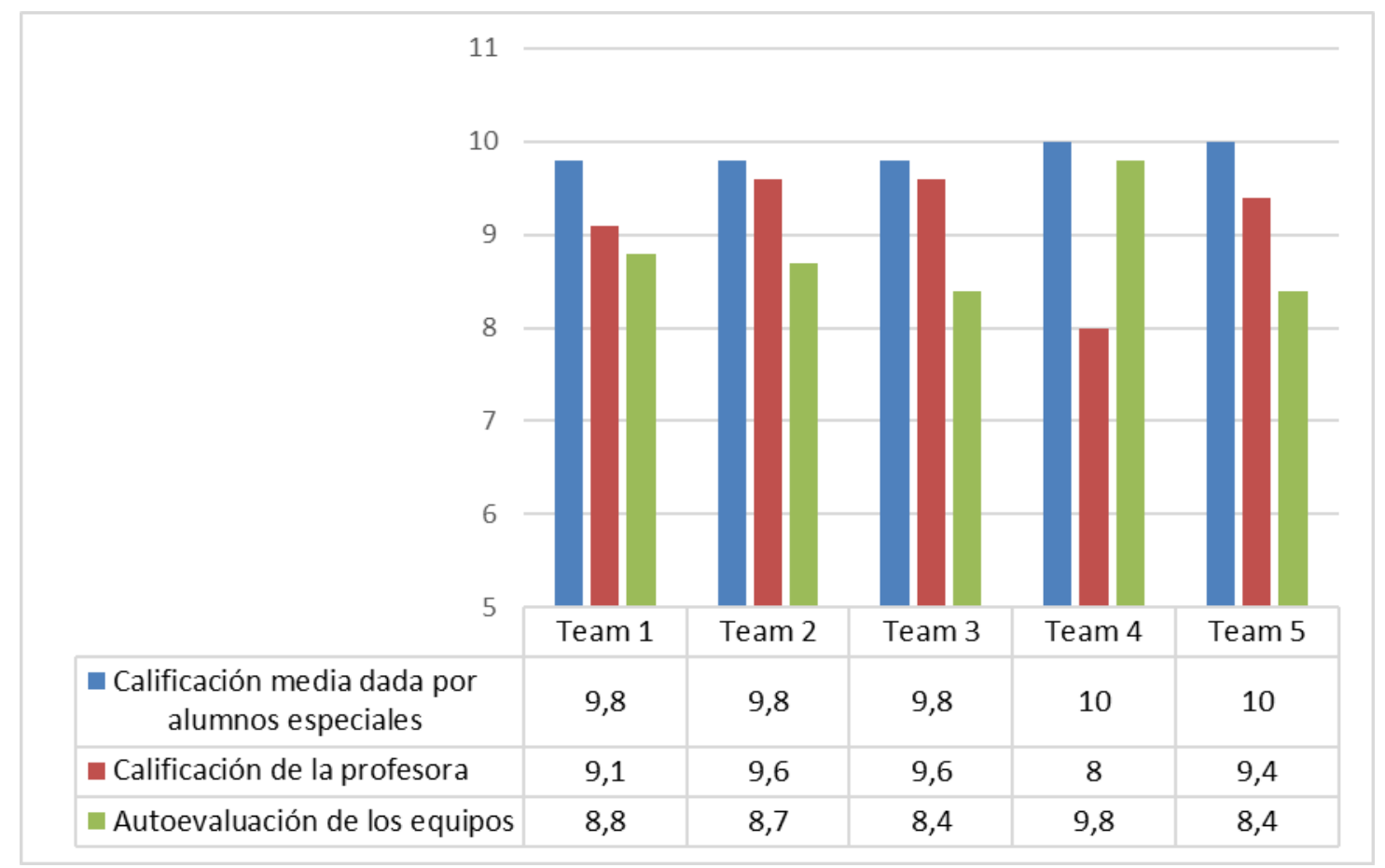

Figura 2. Calificaciones de las presentaciones por parte de los tres sujetos de la evaluación curso 2017-18

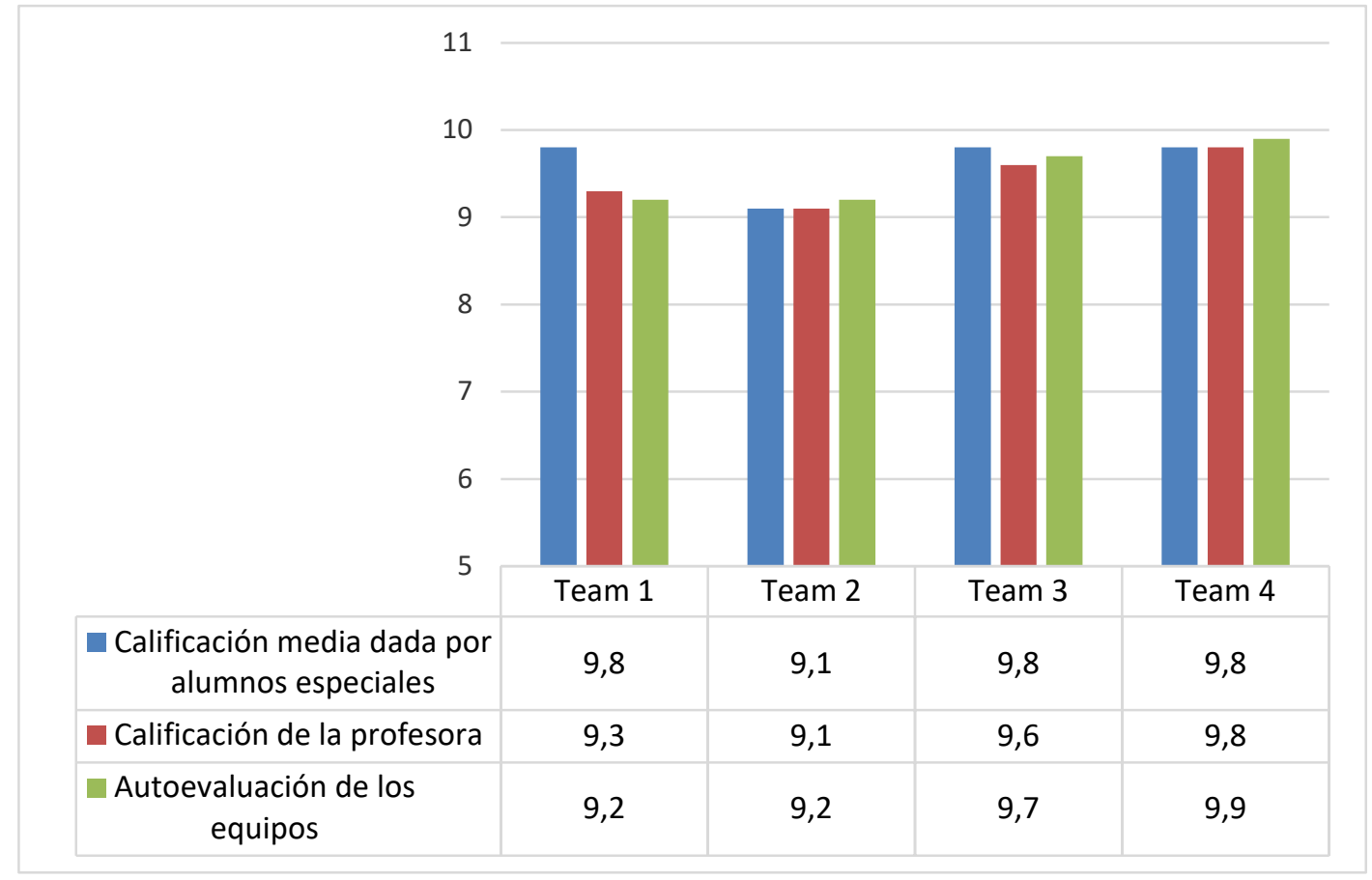

Figura 3. Calificaciones de las presentaciones por parte de los tres sujetos de la evaluación curso 2018-19

Los componentes de evaluación del proyecto, tanto los comunes de las presentaciones como los específicos usados por la profesora, se recogen en la tabla 3. 
Tabla 3.

Componentes de evaluación del proyecto de ApS

\begin{tabular}{|c|c|}
\hline COMPONENTES EVALUABLES & Proporción \\
\hline Contenidos generales (domino del tema) & $10 \%$ \\
\hline Guion de la presentación & $10 \%$ \\
\hline $\begin{array}{l}\text { Media de calificaciones de alumnos de La Casa } \\
\text { Grande y de la UCAV* }\end{array}$ & $10 \%$ \\
\hline Participación de todo el equipo en la presentación & $10 \%$ \\
\hline Capacidad de hacer participar a los oyentes & $10 \%$ \\
\hline Uso de materiales y recursos & $10 \%$ \\
\hline Apoyo de medios audiovisuales & $10 \%$ \\
\hline $\begin{array}{l}\text { "Report and reflection of my Service Learning } \\
\text { experience" (composition)* }\end{array}$ & $30 \%$ \\
\hline TOTAL & $100 \%$ \\
\hline
\end{tabular}

*Salvo estos componentes de evaluación en negrilla, todos los demás fueron evaluados además de por la profesora por el grupo actor y receptor del aprendizaje-servicio, y todos los participantes utilizaron esta rúbrica sintética común.

Los resultados muestran que los alumnos de Ingenierías en ambos cursos mostraron una tendencia a infravalorar sus actuaciones, en especial en el curso 2017-18. En contraste, los alumnos receptores del proyecto de ApS siempre tendieron a supervalorarlas. Las calificaciones de la profesora en casi todos los casos representan un término medio entre ambas percepciones (grupo actor y receptor). En cualquier caso, la variación de calificaciones no supera en ningún caso el rango \pm 2 (curso 2017-18) o $\pm 0,6$ (curso 2018-19).

\section{Conclusiones}

Con la realización de este proyecto de Aps se consiguieron objetivos específicos del área de inglés y se desarrollaron competencias como el trabajo en equipo y resolución de problemas, tan fundamentales en el área de ingeniería. Los alumnos han tenido que organizarse y distribuir tareas tanto en la fase de preparación como en la de realización del proyecto. También en la de evaluación han tenido que reflexionar juntos sobre su actuación y sacar conclusiones sobre la experiencia vivida en equipo. La utilización de un tipo de evaluación formativa con diversos sujetos, medios e instrumentos ha permitido abarcar el proyecto en toda su complejidad y analizar el entramado de 
relaciones y actuaciones de una forma más completa y objetiva. La evaluación compartida da protagonismo a los distintos participantes en el proyecto de ApS y permite valorar más justamente la consecución de objetivos. En nuestro caso, se requirió adaptar las rúbricas usadas por los alumnos con capacidades diferentes simplificando el vocabulario. Estos alumnos se beneficiaron de la evaluación compartida al sentirse incluidos en el proceso de aprendizaje y poder valorar la actuación de sus compañerosprofesores. Éstos a su vez pudieron comprobar cómo sus compañeros-alumnos percibían sus actuaciones y en qué medida alcanzaban los objetivos de enseñanzaaprendizaje propuestos.

\section{Referencias}

Austin, M.J., \& Rust, D.Z. (2015). Developing an Experiential Learning Program: Milestones and challenges. International Journal of Teaching and Learning in Higher Education, 27(1), 143-153.

Hamodi, C., López Pastor, V.M., \& López Pastor, A.T. (2015). Medios, técnicas e instrumentos de evaluación formativa y compartida del aprendizaje en Educación Superior. Perfiles Educativos, 37(147), 146-161.

Hart, S. (2015). Engaging the learner: The ABC's of Service-Learning. Teaching and Learning in Nursing, 10, 76-79.

Richards, E.A., \& Novak, J.C. (2010). From Biloxi to Cape Town. Curricular integration of Service Learning. Journal of Community Health Nursing, 27, 4650. 